\title{
Falls and fear of falling among Israeli community-dwelling older people: a cross- sectional national survey
}

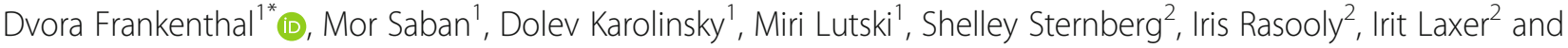 \\ Inbar Zucker ${ }^{1,3}$
}

\begin{abstract}
Background: Falls and fear of falling are a major problem for older people and a leading cause of functional decline and institutionalization. There is limited data on the prevalence of falls in a 12-month period among Israeli older adults. Our main objective was to evaluate the prevalence of falls among Israeli community-dwelling older people aged $\geq 65$ years and to identify factors associated with falls and fear of falling.

Methods: A national cross-sectional interview survey was conducted between February 2018 and April 2019 by the Israeli Center for Disease Control. The prevalence of falls was assessed by asking participants about falling within the 12 months prior to the survey. Fear of falling was assessed by asking participants about the fear of future falls. Multivariate analysis was used to identify factors associated with falls and with fear of falling.

Results: From 5281 households that were eligible for inclusion in this study, 3242 participants (61.4\%) completed the survey. Falling at least once in the past year was reported by $23.8 \%$ of the respondents and fear of falling by $48.2 \%$. The majority of the participants (91.1\%) reported that they had never received any instruction about fall prevention from their medical care provider. In the multivariate analysis, falls and fear of falling were each a risk factor for the other; and were also significantly associated with female gender, major functional difficulties, the use of walking aids, cardiac disease, diabetes mellitus and psychotropic medications.

Conclusion: The prevalence of falls and fear of falling among Israeli community-dwelling older people is comparable to the rates published in other countries. Efforts should be made to increase awareness about falls and their health consequences among older people. The development of specific interventions to target those at higher risk for falls and fear of falling is strongly recommended.
\end{abstract}

Keywords: Falls, Fear of falling, Geriatrics, Israel, Older people

\section{Introduction}

Falls are a major problem for older adults and a leading cause of injury-related death, functional decline and early entry into residential care $[1,2]$. A fall is defined by the World Health Organization (WHO) as an event that results in a person coming to rest inadvertently on the

\footnotetext{
* Correspondence: Dvora.frankenthal@moh.gov.l

${ }^{1}$ Israel Center for Disease Control (ICDC), Ministry of Health, Ramat-Gan, Israel Full list of author information is available at the end of the article
}

ground or floor, or other lower level [3]. About 20-40\% of the population aged 60 years or over have been described as reporting at least one fall in a year [4-6]. The etiology of falls is multifactorial and interventions that focus on risk factor reduction are important to prevent falls among older persons [7]. Among the most important consequences of falls are the psychological ones which include a fear associated with falls. This can lead to disability and loss of independence [8]. 
Fear of falling (FOF) is defined as a concern about falling, and is accompanied by loss of balance, loss of confidence and avoidance of activities [9]. FOF usually arises after a fall but can also present without a history of falls [10]. Great variability in the prevalence of FOF has been reported, ranging from $3 \%$ to as high as $85 \%$ of community-dwelling older fallers $[8,10]$.

On November 2017, the Israeli Ministry of Health $(\mathrm{MOH})$ initiated a national program with the aim of reducing the incidence of falls in the older population. The current survey was conducted within the framework of this program. There is limited data on the prevalence of falls in a 12-month period among Israeli Jewish and Arab community-dwelling older adults. The primary objective of the survey was to assess the prevalence of falls among Israeli community-dwelling older adults aged $\geq 65$ years. The aim was to provide primary data of the national rates of self-reported falls that would serve as a baseline for future evaluations of the effectiveness of this national program. A secondary objective was to investigate factors associated with falls and FOF. Identifying risk factors for falls and at-risk populations might help policy makers to develop specific interventions and prevention strategies to target those at highest risk.

\section{Methods}

\section{Survey design and population}

A national cross-sectional telephone interview survey of households in Israel was conducted between February 2018 and April 2019 by the Israeli Center for Disease Control. A random sample of telephone numbers (mobile and landline) of Jewish and Arab households was extracted. The sample was proportionate to the population geographic distribution. Households were considered non-eligible and were excluded from the sample if they fulfilled at least one of the following criteria: there was no resident older than 65 years, the residents did not speak Hebrew or Arabic, the residents were unable to complete the questionnaire due to mental or physical disability, and the telephone line was for business or was disconnected. Households were identified as nonrespondents (with unknown eligibility) after 8 failed attempts to make contact. Nonresponses included outright refusals to participate, partially completed interviews, and repeated postponements.

\section{Questionnaire and data collection}

Information was collected by means of a structured questionnaire, using a computer-assisted telephone interview (CATI) system. The questionnaire was administered over the telephone in Hebrew and Arabic by trained interviewers from the corresponding population groups. Information collected by the questionnaire included demographic characteristics, health status (comorbidities, medication use, vision and hearing difficulties), physical activity, functional difficulties (physical and cognitive) and falling-related questions (falls in the preceding year, place of fall, fall-related injuries, fear of falling). The Hebrew questionnaire was translated into Arabic and translated back to Hebrew for quality control. The Hebrew and Arabic questionnaires were pretested on a pilot sample to ensure that the survey was understood by all the respondents.

\section{Definitions}

All the variables were based on self-report. The definitions of key variables for the analysis were based on survey questions.

\section{Falling and fear of falling}

The primary outcome measure was the rate of falling, defined as the presence of one or more self-reported falls in the 12 months prior to the survey. This was assessed by asking participants 'Have you fallen during the previous year?" (yes/no). If the response was "don't know" or "don't remember", the interview was excluded from the data analysis. If the response was positive, the respondent was asked, "In the past 12 months, how many times did you fall?" In addition, participants were asked if they had ever received instructions about fall prevention from their medical care provider. The secondary outcome measure was FOF, assessed by asking all participants, those who had fallen and those who had not, "Are you afraid of future falling?" (yes/no). If the response was positive, the respondent was asked, "Due to fear of falling, have you stopped doing certain activities you liked or used to do?" (yes/no).

\section{Variables}

We used previous research and expert advice from the Ministry of Health geriatric division to determine which variables were associated with falling and FOF among older people $[10,11]$. These variables included demographic characteristics, health status and functional limitations. Chronic diseases were assessed by asking the participant, "Has a doctor ever told you that you had any of the following health conditions: a history of heart attack, cardiac disease, a history of stroke, diabetes, Parkinson's disease, arthritis, depression or anxiety?". Daily medicine intake was also self-reported and was assessed by asking "How many daily medications do you usually take (excluding vitamins or dietary supplements)?". The use of sleeping medications and mood medications was assessed by asking "Do you usually use sleeping medications?" and "Do you usually use medications to improve your mood?". These were multiple-choice questions with 3 possible answers ("yes always", "yes sometimes", "never"). For the current analysis, these 3 categories were 


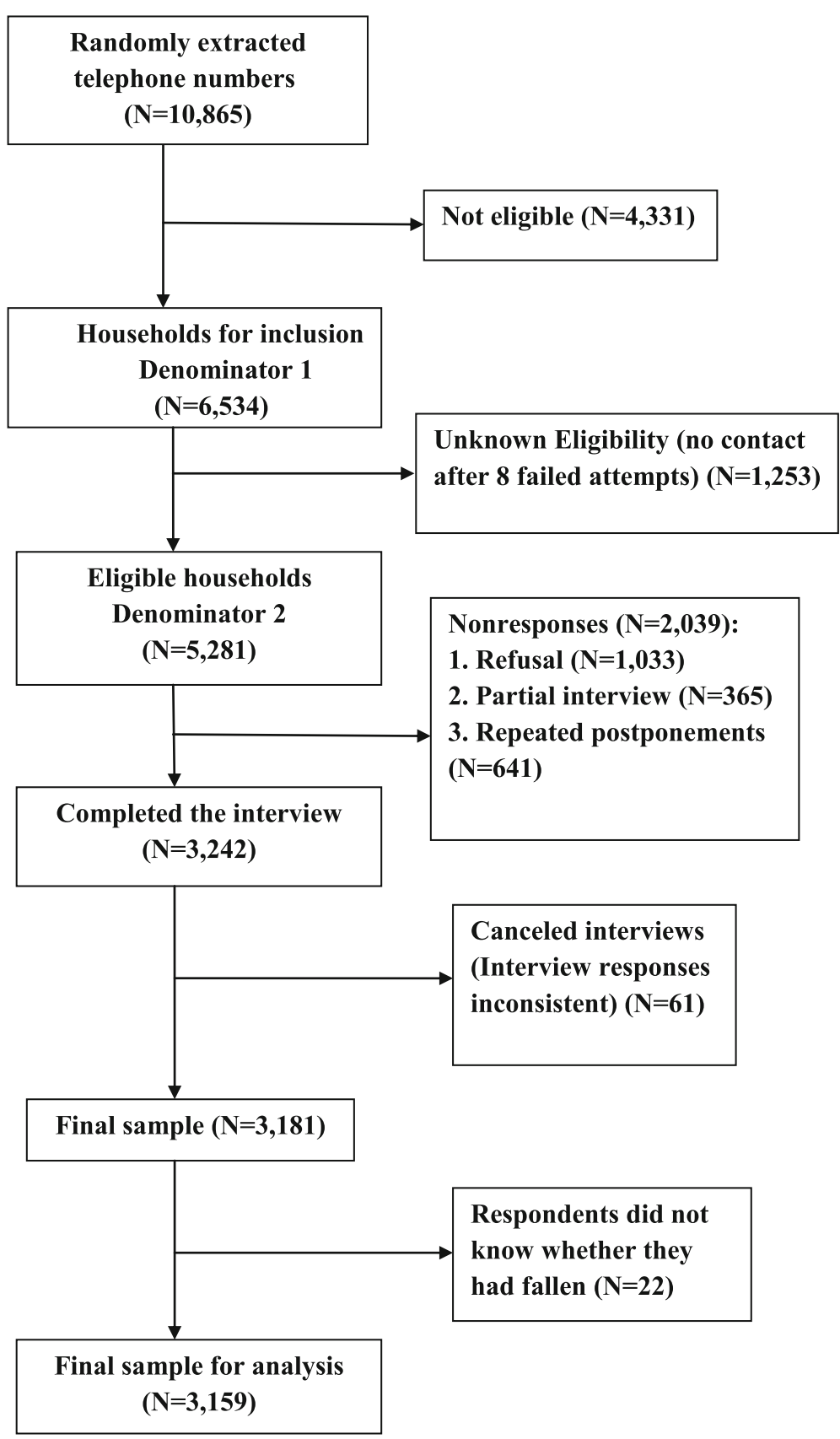

Fig. 1 Outcome of household telephone-calls

grouped into 2 categories (yes/no). Functional status was assessed by asking participants "Do you have any difficulties in dressing or bathing?" and "Do you have any difficulties in doing household activities such as cleaning and shopping?" and "Do you have any difficulties in memory or concentration?" These were multiple-choice questions with 4 possible answers (no difficulty, little difficulty, major difficulty, and no ability to do such activities). The latter two categories were grouped into one for the analysis. Vision difficulties were assessed by the question: "Do you have vision problems?" (yes/no). Hearing difficulties were assessed by 2 questions: "Do you use a hearing aid?" (yes/ no) and "Do you have hearing difficulties?" (yes/no). Hearing difficulties were defined as a positive answer to at least one of these questions. Physical activity was assessed by asking "Do you usually do any sports or physical activity in your free time to keep yourself fit and healthy?" (yes/no). 
Table 1 Demographic characteristics of the respondents by whether they fell during the past 12 months

\begin{tabular}{|c|c|c|c|c|}
\hline \multirow[b]{2}{*}{ Variable } & \multirow[b]{2}{*}{$\begin{array}{l}\text { All } \\
\text { n, (\%) }\end{array}$} & \multicolumn{2}{|c|}{ Falls $^{\mathrm{a}}$ in the past 12 months } & \multirow[b]{2}{*}{$P$ value } \\
\hline & & $\begin{array}{l}\text { Yes } \\
\text { n, (\%) }\end{array}$ & $\begin{array}{l}\text { No } \\
\text { n, (\%) }\end{array}$ & \\
\hline Age & & & & $0.001>$ \\
\hline $65-69$ & $602(19.1 \%)$ & $107(14.2 \%)$ & $495(20.6 \%)$ & \\
\hline $70-74$ & $907(28.7 \%)$ & $173(23.0 \%)$ & $734(30.5 \%)$ & \\
\hline $75-79$ & $872(27.6 \%)$ & $241(32.0 \%)$ & $631(26.2 \%)$ & \\
\hline$\geq 80$ & $778(24.6 \%)$ & $232(30.8 \%)$ & $546(22.7 \%)$ & \\
\hline Gender & & & & $0.001>$ \\
\hline Male & $1350(42.7 \%)$ & $221(29.3 \%)$ & $1129(46.9 \%)$ & \\
\hline Female & 1809 (57.3\%) & $532(70.7 \%)$ & 1277 (53.1\%) & \\
\hline Population group & & & & 0.56 \\
\hline Jewish & $2072(65.6 \%)$ & $500(66.5 \%)$ & $1572(65.3 \%)$ & \\
\hline Arab & 1087 (34.4\%) & $253(33.5 \%)$ & $834(34.7 \%)$ & \\
\hline Years of schooling & & & & $0.001>$ \\
\hline$\leq 12$ & $1753(56.9 \%)$ & $458(62.9 \%)$ & $1295(55.1 \%)$ & \\
\hline$>12$ & $1327(43.1 \%)$ & $270(37.1 \%)$ & $1057(44.9 \%)$ & \\
\hline Marital Status & & & & $0.001>$ \\
\hline Married or living with a partner & $2160(69.1 \%)$ & $431(57.7 \%)$ & $1729(72.7 \%)$ & \\
\hline Single or widowed & 159 (5.1\%) & $43(5.8 \%)$ & $116(4.9 \%)$ & \\
\hline Separated & $805(25.8 \%)$ & $273(36.5 \%)$ & $532(22.4 \%)$ & \\
\hline
\end{tabular}

\section{Sample size}

The prevalence of falls among the elderly in accordance with the literature was estimated as 30\% [4-6]. The margin of error and confidence level were defined as 2.4 and $95 \%$ respectively. The minimum recommended sample size to meet this criterion was 3000 participants. The sample size was calculated using Epi Info, an open source calculator [12].

\section{Statistical analysis}

Data were analyzed using SPSS version 25 (SPSS Inc., Chicago, IL, USA). For the descriptive analysis, we calculated the prevalence and percentages for all variables. The percentages of variables were weighted for population groups, age and gender. The Pearson's Chi-square test was used to compare categorical variables between those who reported a fall in the preceding year and those who did not. Bonferroni corrections were made for multiple comparisons. Multivariate analysis using a backward stepwise logistic regression model was applied to examine risk factors associated with falls and FOF. The following variables were entered in the multivariate logistic regression model: sociodemographic factors (population group, age, gender and education), health-related factors (comorbidities and the use of medications), cognitive and physical difficulties, physical activity and fall- related factors. A $P$ value of $<0.05$ was considered statistically significant.

\section{Ethics statement}

According to Israeli legislation, telephone health surveys, as described herein, are conducted within the regulatory capacity of the Israeli Center for Disease Control and do not require an approval of an ethics committee. Therefore, approval of an ethics committee was not needed for this data collection and analysis. Oral informed consent for each participant was obtained after a brief explanation about the health survey, including the objectives and importance.

\section{Results}

A random sample of telephone numbers of 10,865 households was extracted: 5000 Jewish households and 5865 Arab households. After excluding non-eligible households and households with unknown eligibility (non-respondents), a total of 5281 households remained; of them 3242 participants completed the survey (Fig. 1). The response rate was $49.6 \%$ (if the unknown eligible households were considered, denominator 1) and $61.4 \%$ (if the unknown eligible households were not considered, denominator 2). After excluding 61 inconsistent interviews and 22 interviews of respondents who reported not knowing whether they had fallen within the last year, 
Table 2 Health characteristics of the study participants by whether they fell in the past 12 months

\begin{tabular}{|c|c|c|c|c|}
\hline \multirow[b]{2}{*}{ Variable $^{\mathbf{b}}$} & \multirow[b]{2}{*}{$\begin{array}{l}\text { All } \\
\mathrm{n}(\%)\end{array}$} & \multicolumn{2}{|c|}{ Falls ${ }^{\mathrm{a}}$ in the past 12 months } & \multirow[b]{2}{*}{$P$ value } \\
\hline & & $\begin{array}{l}\text { Yes } \\
\text { n (\% within fallers) }\end{array}$ & $\begin{array}{l}\text { No } \\
\text { n (\% within non-fallers) }\end{array}$ & \\
\hline Difficulties in bathing or dressing & & & & $0.001>$ \\
\hline No difficulty & $2305(73.4 \%)$ & $389(52.3 \%)$ & $1916(80.0 \%)$ & \\
\hline Little difficulty & $439(14.0 \%)$ & $143(19.2 \%)$ & $296(12.4 \%)$ & \\
\hline Major difficulty/Disabled & $396(12.6 \%)$ & $212(28.5 \%)$ & $184(7.7 \%)$ & \\
\hline Difficulties in doing household activities & & & & $0.001>$ \\
\hline No difficulty & $1811(58.2 \%)$ & $260(35.4 \%)$ & $1551(65.3 \%)$ & \\
\hline Little difficulty & $556(17.9 \%)$ & $144(19.6 \%)$ & $412(17.3 \%)$ & \\
\hline Major difficulty/Disabled & $744(23.9 \%)$ & $331(45.0 \%)$ & $413(17.4 \%)$ & \\
\hline Memory and concentration difficulties & & & & $0.001>$ \\
\hline No difficulty & 1916 (61.9\%) & $354(48.8 \%)$ & $1562(65.9 \%)$ & \\
\hline Little difficulty & $978(31.6 \%)$ & $274(37.8 \%)$ & $704(29.7 \%)$ & \\
\hline Major difficulty/Disabled & $203(6.6 \%)$ & $97(13.4 \%)$ & $106(4.5 \%)$ & \\
\hline Difficulties in walking & & & & $0.001>$ \\
\hline No difficulty & $1495(47.8 \%)$ & $206(27.6 \%)$ & $1289(54.1 \%)$ & \\
\hline Little difficulty & $848(27.1 \%)$ & $195(6.2 \%)$ & $653(27.4 \%)$ & \\
\hline Major difficulty/Disabled & $721(23.0 \%)$ & $306(41.0 \%)$ & $415(17.4 \%)$ & \\
\hline No mobility & $66(2.1 \%)$ & $39(5.2 \%)$ & $27(1.1 \%)$ & \\
\hline Impaired vision, yes, n (\%) & $862(27.5 \%)$ & $276(37.1 \%)$ & $586(24.5 \%)$ & $0.001>$ \\
\hline Hearing problems, yes, $n(\%)$ & 969 (32.5\%) & $303(42.5 \%)$ & $666(29.4 \%)$ & $0.001>$ \\
\hline Use of walking aids, yes, $n(\%)$ & $592(19.2 \%)$ & $263(36.9 \%)$ & $329(13.9 \%)$ & $0.001>$ \\
\hline Physical activity & & & & $0.001>$ \\
\hline Yes, n (\%) & $1539(48.9 \%)$ & 297 (39.7\%) & $1242(51.8 \%)$ & \\
\hline No, n (\%) & 1608 (51.1\%) & $451(60.3 \%)$ & $1157(48.2 \%)$ & \\
\hline \multicolumn{5}{|l|}{ Morbidity } \\
\hline History of heart attack, yes, n (\%) & $443(14.1 \%)$ & $122(16.4 \%)$ & $321(13.4 \%)$ & 0.046 \\
\hline Cardiac (arrhythmia/chronic heart failure), yes, n (\%) & $630(21.1 \%)$ & $227(32.9 \%)$ & $403(17.6 \%)$ & $0.001>$ \\
\hline History of stroke, yes, n (\%) & $266(8.5 \%)$ & $96(13.0 \%)$ & $170(7.2 \%)$ & $0.001>$ \\
\hline Diabetes mellitus, yes, n (\%) & $1058(33.8 \%)$ & $315(42.1 \%)$ & $743(31.2 \%)$ & $0.001>$ \\
\hline Parkinson, yes, n (\%) & $30(1.0 \%)$ & $16(2.2 \%)$ & $14(0.6 \%)$ & 0.001 \\
\hline Arthritis, yes, n (\%) & $572(18.7 \%)$ & $203(28.4 \%)$ & $369(15.7 \%)$ & $0.001>$ \\
\hline Depression/Anxiety, yes, n (\%) & $485(15.6 \%)$ & $204(27.9 \%)$ & $281(11.8 \%)$ & $0.001>$ \\
\hline Use of medications (number) & & & & $0.001>$ \\
\hline 0 & $346(11.0 \%)$ & $47(6.3 \%)$ & $299(12.4 \%)$ & \\
\hline $1-4$ & $1776(56.3 \%)$ & $339(45.1 \%)$ & $1437(59.8 \%)$ & \\
\hline $5-8$ & $729(23.1 \%)$ & $233(31.0 \%)$ & $496(20.6 \%)$ & \\
\hline$>8$ & $306(9.7 \%)$ & $133(17.7 \%)$ & $173(7.2 \%)$ & \\
\hline \multicolumn{5}{|l|}{ Type of medications } \\
\hline Sleeping medications, yes, n (\%) & $578(18.4 \%)$ & $200(26.9 \%)$ & $378(15.8 \%)$ & $0.001>$ \\
\hline Mood medications, yes, n (\%) & $351(11.3 \%)$ & $148(20.1 \%)$ & $203(8.5 \%)$ & $0.001>$ \\
\hline Body mass index (BMI kg/m²) & & & & 0.43 \\
\hline BMI-Underweight $(<18.5)$ & $33(1.2 \%)$ & $6(0.9 \%)$ & $27(1.3 \%)$ & \\
\hline BMI-Normal weight (18.5-24.9) & $883(31.4 \%)$ & $197(30.2 \%)$ & $686(31.8 \%)$ & \\
\hline
\end{tabular}


Table 2 Health characteristics of the study participants by whether they fell in the past 12 months (Continued)

\begin{tabular}{|c|c|c|c|c|}
\hline \multirow[b]{2}{*}{ Variable $^{\mathbf{b}}$} & \multirow[b]{2}{*}{$\begin{array}{l}\text { All } \\
\text { n (\%) }\end{array}$} & \multicolumn{2}{|c|}{ Falls ${ }^{\mathrm{a}}$ in the past 12 months } & \multirow[b]{2}{*}{$P$ value } \\
\hline & & $\begin{array}{l}\text { Yes } \\
\mathrm{n} \text { (\% within fallers) }\end{array}$ & $\begin{array}{l}\text { No } \\
\mathrm{n} \text { (\% within non-fallers) }\end{array}$ & \\
\hline BMI-Overweight (25.0-29.9) & $1234(43.9 \%)$ & $282(43.2 \%)$ & $952(44.1 \%)$ & \\
\hline BMI-Obese $(\geq 30)$ & $661(23.5 \%)$ & $168(25.7 \%)$ & $493(22.8 \%)$ & \\
\hline Having fear of falling, yes, $n(\%)$ & $1416(48.2 \%)$ & $507(69.8 \%)$ & $909(41.4 \%)$ & $0.001>$ \\
\hline Interruption of activities due to fear of falling, yes, $\mathrm{n}(\%)$ & $761(56.0 \%)$ & $313(65.2 \%)$ & $448(51.0 \%)$ & $0.001>$ \\
\hline
\end{tabular}

${ }^{\mathrm{a}}$ At least one fall in the past 12 months

${ }^{b}$ Variables were weighted by population group, age and gender

the sample for analysis included 3159 participants (2072 Jews and 1087 Arabs). Basic demographic characteristics are shown in Table 1. The mean age of the participants was $75.11 \pm 6.15$ years. The majority were women (1809, $57.3 \%$ ), and married or living with a partner (2160, $69.1 \%)$.

\section{Falls}

In this survey, $23.8 \%$ of the respondents reported falling at least once in the past 12 months. Of them, $55.4 \%$ reported falling once, $21.7 \%$ twice, $11.1 \%$ three times and $11.8 \%$ four times or more. Women $(70.7 \%)$ were more likely to report falling than men $(29.3 \%, P<0.001)$ (Table 1). The proportion of adults who fell increased

Table 3 Adjusted $^{\mathrm{a}}$ odds ratios (OR) for associations between risk factors and falls

\begin{tabular}{lll}
\hline \multirow{2}{*}{ Variable } & \multicolumn{2}{l}{ Falls in the past $\mathbf{1 2}$ months } \\
\cline { 2 - 3 } Age & OR & Cl 95\% \\
Gender & 1.03 & $1.01-1.05$ \\
$\quad$ Male & 1 (Ref) & - \\
$\quad$ Female & 2.03 & $1.58-2.61$ \\
Difficulties in bathing or dressing & \\
$\quad$ No difficulty & 1 (Ref) \\
Little difficulty & 1.50 & - \\
$\quad$ Major difficulty/Disabled & 2.50 & $1.07-2.10$
\end{tabular}

Memory and concentration difficulties

\begin{tabular}{lll} 
No difficulty & 1 (Ref) & - \\
Little difficulty & 1.31 & $1.02-1.69$ \\
Major difficulty/Disabled & 1.77 & $1.09-2.88$ \\
Hearing problems (yes) & 1.32 & $1.03-1.69$ \\
Diabetes mellitus (yes) & 1.35 & $1.06-1.72$ \\
Cardiac disease (yes) & 1.41 & $1.08-1.84$ \\
Mood medications (yes) & 1.66 & $1.18-2.34$ \\
Use of walking aids (yes) & 1.54 & $1.11-2.15$ \\
Fear of falling (yes) & 1.66 & $1.29-2.13$ \\
\hline
\end{tabular}

${ }^{a}$ Variables that were included in the model but were not statistically significant: population group, education, number of medications, sleep medications, impaired vision, physical activity, arthritis and Parkinson's disease with age $(P<0.001)$. There was no significant difference in the reported prevalence of falling between the Israeli Arab and Jewish population groups $(P=0.56)$. Regarding the place of fall, $45.3 \%$ had fallen outdoors (streets, parks), $45.5 \%$ in their own homes and 9.2\% indoors but not in their own house. The majority of the participants (91.1\%) reported that they had never received any instruction about fall prevention from their medical care provider. Furthermore, among those who had fallen in the previous year only $11.9 \%$ received any fall prevention education. Fall-related fractures were reported by $19.7 \%$ of the participants. Arm or elbow fractures accounted for $41.3 \%$ of the total fractures, followed by leg or ankle fractures (19.3\%). All the known risk factors for falls that

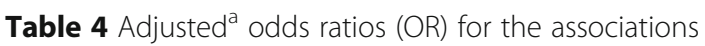
between risk factors and fear of falling

\begin{tabular}{lll}
\hline & \multicolumn{2}{l}{ Fear of falling } \\
\cline { 3 - 3 } Variable & OR & $\mathrm{Cl} 95 \%$ \\
\hline Gender & & \\
$\quad$ Male & 1 (Ref) & \\
$\quad$ Female & 2.87 & $2.33-3.53$ \\
Difficulties in bathing or dressing & & \\
$\quad$ No difficulty & 1 (Ref) & \\
Little difficulty & 2.37 & $1.70-3.31$ \\
$\quad$ High difficulty/Disabled & 3.14 & $1.94-5.07$
\end{tabular}

\section{Memory and concentration difficulties}

$\begin{array}{lll}\text { No difficulty } & 1 \text { (Ref) } & \\ \text { Little difficulty } & 1.63 & 1.31-2.02 \\ \text { High difficulty/Disabled } & 2.81 & 1.51-5.22 \\ \text { Sleep medications (yes) } & 1.62 & 1.23-2.13 \\ \text { Use of walking aids (yes) } & 1.83 & 1.29-2.58 \\ \text { Diabetes mellitus (yes) } & 1.32 & 1.07-1.63 \\ \text { Cardiac disease (yes) } & 1.65 & 1.28-2.12 \\ \text { Arthritis (yes) } & 1.57 & 1.17-2.12 \\ \text { Falls during the last year (yes) } & 1.69 & 1.31-2.18\end{array}$

${ }^{a}$ Variables that were included in the model but were not statistically significant: population group, age, education, number of medications, mood medications, impaired vision, hearing problems, physical activity and Parkinson's disease 
were examined were significantly higher among those who fell than among those who did not (Table 2).

The multivariate logistic regression analysis (Table 3) found that falls were associated with older age, female gender, major difficulty in bathing or dressing, the use of walking aids, major difficulty in memory and concentration, the use of mood medications, hearing problems, cardiac disease, diabetes mellitus and FOF.

\section{Fear of falling}

Fear of falling was reported by 1416 (48.2\%) participants and was significantly more prevalent among those who had fallen in the previous year (69.8\%) than among those who had not $(41.4 \%, P<0.001)$. Interruption of activities due to FOF was reported significantly more among fallers $(65.2 \%)$ than non-fallers $(51.0 \%, P<0.001)$. Multivariate logistic regression analysis (Table 4 ) showed that FOF was associated with female gender, major difficulty in bathing or dressing, major difficulty in memory and concentration, the use of sleep medications, cardiac disease, diabetes mellitus, arthritis, the use of walking aids and falls during the last year.

\section{Discussion}

In this national survey, $23.8 \%$ of Israeli communitydwelling people aged $\geq 65$ years reported falling at least once in the past 12 months. The prevalence of falls in a 12 -month period reported in the current study is consistent with the prevalence reported among communitydwelling older adults aged $\geq 65$ years in other population-based studies: $20.0 \%$ in Canada, $24.4 \%$ in the UK and 22.0 and $28.7 \%$ in the USA [5, 13-15]. Risk factors that were associated with falls and FOF are consistent with those reported in other studies and include female gender $[5,11]$, major functional difficulties [16-18], comorbidity [16, 17], the use of walking aids [11, 19, 20] and psychotropic medications $[21,22]$. The literature suggests that fall rates may differ between different racial and ethnic groups [23]. In the current study, the prevalence of falls did not differ between the Jewish and Arab participants who account for approximately one-fifth of the total Israeli population.

FOF was reported by nearly half of the participants. FOF usually arises after a fall but can also occur without a history of falls [24]. FOF was significantly more prevalent among participants who had fallen in the previous year $(69.8 \%)$ but also highly prevalent $(41.4 \%)$ among those who had not fallen. This finding highlights the importance of screening for FOF in the older population. Indeed, in a systematic review that included 21 studies, the prevalence of FOF ranged from 21 to $85 \%$ among community-dwelling older adults, and over $50 \%$ of people with FOF did not experience a fall [10].
The current study showed that falls and FOF were each a risk factor for the other. Friedman et al. showed that a person who has one of these factors is at risk for developing the other [24]. The authors showed that a "vicious cycle" exists between falls, FOF, and the many adverse outcomes that can result, such as functional decline, a decrease in quality of life, and institutionalization.

The current study demonstrated a higher rate of interruption of activities due to FOF among those who fell than among those who did not. Delbaere et al. showed that this pattern might fuel fear and avoidance, and cause further deterioration of physical performance and increased risk of falls in the long term [25].

Notably, fall prevention interventions have been shown to reduce both the risk of falling and FOF among community-dwelling older adults $[26,27]$. The majority of the participants in this survey $(91.1 \%)$ reported that they had never received any instruction about fall prevention from their medical care provider. Among those who had fallen in the previous year only $11.9 \%$ received any fall prevention education. Healthcare professionals have a major role in increasing awareness about falls and in educating older people about the risk factors associated with falls [26]. The current findings support the importance of the national program for falls prevention whose aims are to identify older people at risk for falls and to develop appropriate falls prevention interventions.

This study has some limitations. First, the data collected were self-reported and subject to recall bias. Some of the participants may have under-reported falls. This would result in a reported prevalence of falls that is lower than the actual rate. Second, our results cannot be generalized to the entire population over 65 years old as the survey did not include people in long-term care facilities who are at higher risk of falls. Third, the crosssectional study design does not enable determining causal relations of falls or FOF with associated factors. The strength of this study is that it is a national survey that included respondents from the two main population groups in Israel.

\section{Conclusions}

The current findings support the national program for falls prevention and indicate that it should focus not only on falls but also on FOF among the older population. The current findings could assist in the development of specific interventions and prevention strategies to target those at higher risk for falls and FOF.

\section{Abbreviations}

FOF: Fear of falling; ICDC: Israeli Center for Disease Control; $\mathrm{MOH}$ : Ministry of Health 


\section{Acknowledgements}

Not applicable.

\begin{abstract}
Authors' contributions
All authors participated in the concept and design of the study. All authors read and approved the final submitted version of the manuscript. DF drafted the manuscript and interpreted the data. MS prepared and analyzed the data. DK coordinated and helped with the acquisition of data. ML, SS, IR, IL, IZ conceptualized the aims and were involved with drafting the survey's questionnaire and with the methodology of the research.
\end{abstract}

\section{Funding}

This research did not receive any specific grant from funding agencies in the public, commercial, or not-for-profit sectors.

\section{Availability of data and materials}

Data are available from the authors upon reasonable request and with permission of the Israel Center of Disease Control.

\section{Declarations}

\section{Ethics approval and consent to participate}

An ethics statement appears at the end of the Methods section.

\section{Consent for publication}

Not applicable.

\section{Competing interests}

The authors declare that they have no competing interests.

\section{Author details}

${ }^{1}$ Israel Center for Disease Control (ICDC), Ministry of Health, Ramat-Gan, Israel. ${ }^{2}$ Israel Ministry of Health, Division of Geriatrics, Jerusalem, Israel. ${ }^{3}$ School of Public Health, Sackler Faculty of Medicine, Tel Aviv University, Tel Aviv, Israel.

Received: 3 June 2020 Accepted: 26 March 2021

\section{Published online: 02 April 2021}

\section{References}

1. McMahon CG, Kenny RA, Bennett K, Bouamra O, Lecky F. Diurnal variation in mortality in older nocturnal fallers. Age Ageing. 2012;41(1):29-35. https:// doi.org/10.1093/ageing/afr119.

2. McMahon CG, Cahir CA, Kenny RA, Bennett K. Inappropriate prescribing in older fallers presenting to an Irish emergency department. Age Ageing. 2014;43(1):44-50. https://doi.org/10.1093/ageing/aft114.

3. WHO. Global report on falls prevention in older age. 2007. Available from: http://www.who.int/ageing/publications/Falls_prevention7March.pdf.

4. Kojima S, Furuna T, Ikeda N, Nakamura M, Sawada Y. Falls among community-dwelling elderly people of Hokkaido, Japan. Geriatr Gerontol Int. 2008;8(4):272-7. https://doi.org/10.1111/j.1447-0594.2008.00476.x.

5. Bergen $G$, Stevens MR, Burns ER. Falls and fall injuries among adults aged $\geq 65$ years- United States, 2014. MMWR Morb Mortal Wkly Rep. 2016;65(37): 993-8. https://doi.org/10.15585/mmwr.mm6537a2.

6. Orces $\mathrm{CH}$. Prevalence and determinants of falls among older adults in Ecuador: an analysis of the SABE I survey. Curr Gerontol Geriatr Res. 2013; 2013:495468.

7. Child S, Goodwin V, Garside R, Jones-Hughes T, Boddy K, Stein K. Factors influencing the implementation of fall-prevention programs: a systematic review and synthesis of qualitative studies. Implement Sci. 2012;7(1):91. https://doi.org/10.1186/1748-5908-7-91.

8. Schoene D, Heller C, Aung YN, Sieber CC, Kemmler W, Freiberger E. A systematic review on the influence of fear of falling on quality of life in older people: is there a role for falls? Clin Interv Aging. 2019;14:701-19. https://doi.org/10.2147/CIA.S197857.

9. Gazibara T, Kurtagic I, Kisic-Tepavcevic D, Nurkovic S, Kovacevic N, Gazibara $T$, et al. Falls, risk factors and fear of falling among persons older than 65 years of age. Psychogeriatrics. 2017;17(4):215-23. https://doi.org/10.1111/ psyg.12217.

10. Scheffer AC, Schuurmans MJ, van Dijk N, van der Hooft T, de Rooij SE. Fear of falling: measurement strategy, prevalence, risk factors and consequences among older persons. Age Ageing. 2008;37(1):19-24. https://doi.org/10.1 093/ageing/afm169.

11. Deandrea S, Lucenteforte E, Bravi F, Foschi R, La Vecchia C, Negri E. Risk factors for falls in community-dwelling older people: a systematic review and meta-analysis. Epidemiology. 2010;21(5):658-68. https://doi.org/10.1097/ EDE.0b013e3181e89905.

12. Dean $A G$, Arner TG, Sunki GG, Friedman R, Lantinga M, Sangam S, et al. Epi Info $^{\mathrm{TM}}$, a database and statistics program for public health professionals. Atlanta: CDC; 2011.

13. Pearson C, St-Arnaud J, Geran L. Understanding seniors' risk of falling and their perception of risk. Health at a Glance, October 2014. Ottawa: Statistics Canada; 2014. [Statistics Canada, Catalogue No.: 82-624-X]

14. Gale CR, Westbury LD, Cooper C, Dennison EM. Risk factors for incident falls in older men and women: the English longitudinal study of ageing. BMC Geriatr. 2018;18(1):117. https://doi.org/10.1186/s12877-018-0806-3.

15. Stevens JA, Ballesteros MF, Mack KA, Rudd RA, DeCaro E, Adler G. Gender differences in seeking care for falls in the aged Medicare population. Am J Prev Med. 2012;43(1):59-62. https://doi.org/10.1016/j.amepre.2012.03.008.

16. Sousa LM, Marques-Vieira CM, Caldevilla MN, Henriques CM, Severino SS, Caldeira SM. Risk for falls among community-dwelling older people: systematic literature review. Rev Gaucha Enferm. 2017;37(4):e55030.

17. Tinetti ME, Mendes de Leon CF, Doucette JT, Baker DI. Fear of falling and fall-related efficacy in relationship to functioning among community-living elders. J Gerontol. 1994;49(3):M140-7. https://doi.org/10.1093/geronj/49.3. M140.

18. Berry SD, Miller RR. Falls: epidemiology, pathophysiology, and relationship to fracture. Curr Osteoporos Rep. 2008;6(4):149-54. https://doi.org/10.1007/s11 914-008-0026-4.

19. Almegbel FY, Alotaibi IM, Alhusain FA, Masuadi EM, Al Sulami SL, Aloushan $A F$, et al. Period prevalence, risk factors and consequent injuries of falling among the Saudi elderly living in Riyadh, Saudi Arabia: a cross-sectional study. BMJ Open. 2018;8(1):e019063. https://doi.org/10.1136/bmjopen-2017019063.

20. Grundstrom AC, Guse CE, Layde PM. Risk factors for falls and fall-related injuries in adults 85 years of age and older. Arch Gerontol Geriatr. 2012; 54(3):421-8. https://doi.org/10.1016/j.archger.2011.06.008.

21. Sharif SI, Al-Harbi AB, Al-Shihabi AM, Al-Daour DS, Sharif RS. Falls in the elderly: assessment of prevalence and risk factors. Pharm Pract (Granada). 2018;16(3):1206. https://doi.org/10.18549/PharmPract.2018.03.1206.

22. Woolcott JC, Richardson KJ, Wiens MO, Patel B, Marin J, Khan KM, et al. Meta-analysis of the impact of 9 medication classes on falls in elderly persons. Arch Intern Med. 2009;169(21):1952-60. https://doi.org/10.1001/a rchinternmed.2009.357.

23. Han BH, Ferris R, Blaum C. Exploring ethnic and racial differences in falls among older adults. J Community Health. 2014;39(6):1241-7. https://doi. org/10.1007/s10900-014-9852-8.

24. Friedman SM, Munoz B, West SK, Rubin GS, Fried LP. Falls and fear of falling: which comes first? A longitudinal prediction model suggests strategies for primary and secondary prevention. J Am Geriatr Soc. 2002;50(8):1329-35. https://doi.org/10.1046/j.1532-5415.2002.50352.x.

25. Delbaere K, Crombez G, Vanderstraeten G, Willems T, Cambier D. Fearrelated avoidance of activities, falls and physical frailty. A prospective community-based cohort study. Age Ageing. 2004;33(4):368-73. https://doi. org/10.1093/ageing/afh 106.

26. Gillespie LD, Robertson MC, Gillespie WJ, Sherrington C, Gates S, Clemson $L M$, et al. Interventions for preventing falls in older people living in the community. Cochrane Database Syst Rev. 2012;(9):CD007146.

27. Hopewell S, Copsey B, Nicolson P, Adedire B, Boniface G, Lamb S. Multifactorial interventions for preventing falls in older people living in the community: a systematic review and meta-analysis of 41 trials and almost 20000 participants. Br J Sports Med. 2019:bjsports-2019-100732.

\section{Publisher's Note}

Springer Nature remains neutral with regard to jurisdictional claims in published maps and institutional affiliations. 